\title{
Del dualismo moderno a la afirmación del cuerpo: poder dominación, subjetividades y saberes implicados*
}

\author{
From modern dualism to the affirmation of the body: power, \\ domination, subjectivities, and knowledge involved.
}

Dra. Lorena González Fuentes**

\section{RESUMEN}

El escrito busca explicitar cómo, a partir de la dicotomía cuerpo razón, pieza clave de la epistemología hegemónica, se configura una subjetividad funcional al orden opresivo imperante. Frente a ello, la apuesta por un conocimiento liberador que transgreda el imperativo de orden exige afirmar el cuerpo. La apuesta por la implicancia y la recuperación de la capacidad creadora posibilita la emergencia de otros saberes y subjetividades.

\section{SUMMARY}

The paper seeks to explain how, based on the body-reason dichotomy, a key piece of hegemonic epistemology, a subjectivity is configured that is functional to the prevailing oppressive order. The commitment to a liberating knowledge that transgresses the imperative of order demands the affirmation of the body. The bet for the implication and recovery of the creative capacity makes possible the emergence of other knowledge and subjectivities.
Palabras clave: epistemología subjetividades, racionalidad, cuerpo, poder dominación

Keywords: epistemology, subjectivities, rationality, body, power, domination

\footnotetext{
* Este artículo forma parte de la Investigación Posdoctoral n³200390 financiada por Fondecyt "Análisis en torno al ejercicio de una Epistemología Situada de la Resistencia: apropiaciones categoriales, éticas y políticas".

** Chilena. Licenciada en Filosofía y Magíster en Filosofía Política y Axiología por la Universidad de Chile. Doctora en Estudios Americanos con especialidad en Pensamiento y Cultura, Universidad de Santiago de Chile. Actualmente se desempeña como académica en la Universidad Católica Silva Henríquez. Educadora popular y feminista. lorena. gonzalez.f@usach.cl. ORCID: https://orcid.org/0000-0002-6779-5552
} 


\section{A modo de introducción}

Habitamos una matriz epistemológica plena de categorizaciones y escisiones que colman el sentido común. Heredera de la impronta cartesiana que gobierna la civilización occidental, la distinción entre cuerpo y razón se ha vuelto una piedra angular. A partir de ella se ha desplegado un ordenamiento que ha permitido la instalación de lo que se concibe por "realidad", tanto en términos teóricos como en las formas de vinculación que esta promueve y soporta.

Teniendo esto en consideración, el escrito busca hacer manifiesto dos elementos fundamentales. En primer lugar, cómo esta dicotomía, propia del dualismo moderno, ha generado no solo una manera de conocer y nombrar el mundo, sino también una propuesta de habitante, de sujeta o sujeto. Esta versión de humanidad no es ingenua ni azarosa. En la medida en que se construye estableciendo la primacía de la razón, se vuelve servil a la instalación y ejercicio del poder dominador.

En segundo lugar el artículo busca evidenciar cómo, a pesar de la consolidación de la matriz hegemónica, las subjetividades ensayan formas de desobedecer irrumpiendo y desnaturalizando el orden imperante. La afirmación del cuerpo y la reivindicación de las afectividades se vuelve el motor del desorden emancipador. A partir de este ejercicio emergen nuevos saberes resonantes con el ímpetu rebelde.

Para lograr esto, la argumentación se organizará en cuatro momentos. El primero instalará algunas consideraciones generales que permitan encuadrar la perspectiva reflexiva que aquí se comparte. Luego, en una segunda instancia, se profundizará en la indivisible relación que se gesta entre epistemología y proyecto antropológico, especificando cómo la subjetividad configurada es tanto producto como productora de dicha episteme. En un tercer apartado se pondrá la atención en el cuerpo y cómo la castración de su capacidad creadora ha sido fundamental para la instalación y perpetuación del orden instituido. En esta sección se buscará hacer evidente la falacia que supone el discurso del saber y poder regente, que declarativamente instala la negación del cuerpo, a pesar de que genera todo un aparataje destinado a subyugarlo. Por ello, su afirmación propicia una apertura que será recogida en el cuarto momento, haciendo hincapié en el protagonismo que tiene la reivindicación del erotismo y las afectividades, tales como la ira y la es- 
peranza, en la construcción de una realidad en la que sea posible habitar vínculos y relaciones sociales que honren la vida en su integralidad.

\section{Consideraciones generales}

La pregunta por conocimientos emancipadores y la apuesta por la creación de saberes y sentidos coherentes con dicho horizonte nos lleva, de manera insoslayable, a cuestionarnos por la matriz epistémica que habitamos y que se nos impone como hegemónica. Precisamente porque forjar categorías, conceptos y/o teorías de este tipo implica irrumpir y exceder el marco de sentidos naturalizado, posibilitando el develamiento de los límites y falacias sobre las que se ha fundamentado su totalización. Por ello, las propuestas epistémicas contrahegemónicas o liberacionistas, tales como aquellas subalternas, decoloniales, feministas, del sur, etc., ponen el acento o se enfrentan a las distintas argucias de la epistemología vigente.

Habitamos una epistemología que se propone como abstracta, neutra y absoluta. Es decir, pretende ser un marco de despliegue que permite circunscribir el curiosear humano a ciertos métodos y técnicas que garanticen que las verdades a las que se llega sean efectivamente veraces y no solo interpretaciones erráticas y contingentes. Cabe recordar que esta epistemología es construida y consolidada por el sujeto moderno quien, frente al desmoronamiento de los relatos y dogmas del medioevo, se encuentra dominado por el miedo y las ansías de control ante la inminente refundación del orden mundial.

Atravesada por ambas disposiciones afectivas - el miedo y la ansiedad por retomar el control-, la subjetividad moderna precisa de la instalación de una nueva regenta absoluta, inmutable, fiable y que, aun cuando se signe como don divino, sea propia de lo humano. Allí es donde la razón hace su aparición triunfal.

No obstante, la necesidad y el deseo modernos, la razón por sí sola no se limita ni se circunscribe. Al contrario, tiende a ir más allá, generando ideas e interpretaciones que, aunque puedan ser profundamente persuasivas, son propias de la imaginación o del mundo onírico y no dan cuenta de la realidad ni mucho menos sirven para contribuir a un conocimiento científico en ciernes. Por eso, la racionalidad para erigirse como panacea debe adecuarse a una versión específica de 
ella. Es decir, para ser funcional a la aspiración de su época necesita ser educada. En este escenario aparecen hombres como Descartes y su búsqueda de un método para dirigir la razón y conocer la Verdad; o el mismo Kant, quien instala la necesidad de revisarla críticamente, para poder constatar los límites, alcances y posibilidades de ella, identificando aquello que va a llamar los usos "lícitos" e "ilícitos" de la razón. Por ello, no es casual que ambos filósofos se hayan posicionado como parte ineludible de los patriarcas de la modernidad.

Como táctica servil a la circunscripción de la razón en su curiosear desbocado, se instala el análisis. Analizar implicar dividir y jerarquizar, identificando vínculos y relaciones para así descubrir el ordenamiento implícito en los fenómenos (Gutiérrez 158). Este adiestramiento de la racionalidad ha hecho que nos aproximemos a la realidad escindiéndola. De este modo, y como nos hace ver Donna Haraway, se va instalando una racionalidad binaria, cargada de dualismo orgánicos y jerárquicos. Entonces, las dicotomías entre mente-cuerpo, animalhumano, organismo-máquina, público-privado, naturaleza-cultura, hombre-mujer, primitivo-civilizado controlan el discurso de occidente (Haraway 59).

Cabe mencionar que en ningún caso esto supone que debamos repudiar y abandonar cualquier forma de análisis. Sin duda es una herramienta útil para conocer e interpretar la realidad. Lo peligrosamente problemático surge cuando esas distinciones, desprendidas del ejercicio analítico, dejan de ser operativas, se absolutizan y se instalan como dicotomías que encasillan, subordinan, idealizan y, a la larga, dogmatizan tanto la manera en que percibimos al mundo como las potencialidades que la praxis engendra. Tal como explicita Alejandra Ciriza, la ciencia y filosofía moderna implican la conversión de la abstracción real en abstracción ideal. Esto conlleva el desprecio por la experiencia, la necesidad de abstraer las diferencias y desplegar una normatividad sobre ellas (98).

Teniendo en cuenta estos elementos esbozados - jerarquización, dicotomías y absolutización-, resulta necesario agudizar la mirada respecto de las implicancias que se desprenden de la dicotomía mente-cuerpo, en la que éste último, junto a las emociones que porta y padece, ha sido denostado y relegado al terreno de lo infantil - entendido como algo negativo desde la lógica adultocéntrica del poder 
(Duarte 2015)—, de lo salvaje - concebido de una manera denigrante frente a lo cual la razón colonial promueve la civilización como certificado de humanización (Fanon 100) - o lo femenino - a partir de la idea moderna que propone que "las mujeres encarnan la animalidad a derrotar, la falta de dominio de sí y la a-historicidad” (Gargallo 64)—. Niños, calibanes y mujeres aparecen como criaturas que deben ser doblegadas, tal como la razón subyuga los sentires y afectividades (González 2018 14). El cuerpo y las pasiones solo pueden tener un papel en la producción de conocimiento en tanto fuente caótica de materia prima que se limita, se encauza y ordena.

Esta supeditación del cuerpo a la razón establece un ordenamiento que excede la dimensión puramente teórica o científica, dando cuenta del correlato ético-político propio de toda epistemología al instalar un proyecto antropológico afín. Dicho de otra manera, lo que aceptamos por "saber" está en estrecha relación con las nociones y prácticas de $\operatorname{poder}^{1}$ que imperan, y que se encarnan en una subjetividad específica que prioriza la racionalidad científica y doblega al cuerpo.

\section{Epistemología y proyecto antropológico: dime qué saber validas y te diré qué propuesta humana engendras}

Afirmar que toda epistemología gesta una versión de humanidad o establecer que, a partir de la concepción de ser humano prevalente, es posible constatar la relación imperante entre poder y saber, son dos formulaciones que se complementan, haciendo énfasis en distintas puertas de acceso a la interrogante que nos convoca y que busca explicitar de qué forma el dualismo cartesiano - y con ello la primacía de lo racional por sobre el cuerpo-, propio del proyecto epistémico moderno y hegemónico, ha sido servil a la instalación de esta civilización basada en el dominio (Pisano 2015) que habitamos.

1 Se está al tanto de lo que el filósofo francés Michel Foucault ha desarrollado. No obstante, en este escrito no se utilizará como referencia. Esto en ningún caso implica una desvalorización de sus aportes, sino que responder a un posicionamiento ético-político en el que se ha optado por reinvindicar a autores y autoras que no suelen ser consideradas dentro del canon filosófico oficial - profundamente masculino, blanco, urbano y eurocentrado-, ya sea por razones geográficas, políticas, de género o raza. 
Para comprender esto es indispensable insistir en el primer aspecto señalado, es decir, aquello que alude a que la epistemología no solo delimita y se expresa en la dimensión teórica, conceptual y/o académica. La praxis epistémica excede esa circunscripción en la medida en que implica una forma de entramarnos con la realidad, o, en palabras de Hugo Zemelman, "un colocarse frente a la circunstancias" (2001 4)2.

Dicha disposición epistémica, ese colocarse frente a la circunstancias, nos habita a todos y promueve un $\operatorname{orden}^{3}$ de y en la realidad. Tal como señala Wallerstein, el modelo epistémico entraña la creación de una visión de mundo (160). Y para lograrlo determina quét cabe en él y qué se excluye; qué se valora y qué se desprecia; qué se nombra y qué se olvida.

Este modo de organización de lo circundante prevalece instalando formatos, develando y construyendo patrones que luego configurarán la norma, lo que se espera. Así se adiestra al pensamiento para que descubra el orden, identifique las relaciones que existen entre los distintos elementos y permita volver a la realidad de una manera menos ingenua (Gutiérrez 158). Todo esto es imprescindible para una civilización que se sostiene, como se mencionaba, en la insistente aspiración de prever, evitar y, entonces, controlar lo inesperado. De ahí que se posicione un paradigma en el que el conocer se vuelve capacidad de dominar, y para ello analiza y fragmenta el mundo hasta que logra identificar las piezas mínimas y claves, los átomos de todo fenómeno -tanto de las ciencias duras como de los procesos sociales-, y, luego, los entrama mediante redes de causalidad, construyendo enlaces de manera jerárquica y unívoca.

Lo que parece ser pasado por alto y que urge evidenciar, es que todo proceso de ordenamiento implica tanto una dimensión objetiva como una subjetiva. Por ello no solo es una disposición que regula nuestra

2 Esto ha sido trabajado en profundidad a lo largo del primer capítulo de mi tesis doctoral titulada Configuración de una Epistemología Situada de la Resistencia: prácticas intelectuales y producción de saberes para la transformación social en Nuestra América. 3 Al respecto cabe mencionar que, en términos etimológicos, "mundo" viene del latín mundus, mundi, y que alude a algo limpio, prolijo, poseedor de un orden que lo armoniza. De ahí que sea posible encontrar su equivalente en la idea griega de "cosmos", que también refiere a un sistema complejo y bello a partir del ordenamiento interno que porta.

4 Y quién. 
mente y razón, sino que se incrusta en los modos de vinculación que desplegamos y que somos capaces de concebir como posibles. De ahí que el orden conforme un mecanismo de construcción de subjetividades (Zemelman 2010 357). Como menciona Raquel Gutiérrez, "El orden es, entonces, un "modo de estar" relacionados entre sí los elementos considerados - objetivo-, y es al mismo tiempo un modo de percibirlos - subjetivo-"(157). El conocimiento y las verdades se depositan sobre cada persona y se ejercen a través de ella condicionando sus impresiones, deseos, necesidades y afectividades.

El moldeamiento de la subjetividad se hace a partir de este paradigma científico mecanicista, que disecciona la experiencia en una serie de engranajes articulados de forma lineal e inequívoca. Por ello requiere, de manera ineludible, controlar aquello que pueda subvertir este modo de funcionamiento, o que ose contravenir el imperativo de orden impuesto. Aquí el sometimiento del cuerpo y la afectividad se vuelve una estrategia fundamental para el poder. Así se factualiza un ser humano en un mundo sin alma y en una corporeidad mecanizada en la cual la mente soberana es la jueza inquisidora, que dirige la voluntad, controla la necesidades, reacciones y acciones de esta "masa" automatizada. Consecuentemente, esta subjetividad, la hija del modelo cartesiano, está basada en el autocontrol, la propiedad de sí y el dominio de sí (Federici 230). Además, fomenta un proyecto antropológico individualista, competitivo y que fundamenta el sentido de la existencia en un proceso ascendente de realización. Al respecto Raquel Gutiérrez dice:

Esta concepción mecánica de la vida como trayectoria del ser humano-átomo, necesariamente y pese a las buenas intenciones, hará prevalecer la competencia y soslayará la cooperación, contribuirá, además, a que se levanten nociones de "éxito", de "fracaso", de "progreso" y de "estancamiento", que tendrán que ver con la adecuación, mayor o menor, de la trayectoria individual con su imagen ideal construida-fijada previamente (215).

Este mismo movimiento que se hace en el campo de la micropolítica del cuerpo individual, se extrapola también al ámbito del cuerpo social. De este modo, va consolidando el funcionamiento político de las comunidades sobre la base de la jerarquización y el cercenamiento de sus capacidades de decidir, intervenir y, en definitiva, de recrear 
el mundo, al centralizarlas en la potestas de aquellos que están en la cúspide social. Así, la doblegación se afianza y configura, como dice Claudia Korol, "un repertorio de acciones sutiles y sistemáticas dirigidas a la construcción de una subjetividad alienada en representaciones del mundo dicotómicas, que garantizan el mando de unos pocos y la obediencia de las mayorías" (2008 28). De este modo el poder de dominación prescribe y formatea aumentando su capacidad de irrigación, en la medida en que no solo se apropia de aquellas subjetividades que directamente son afectadas por su despliegue, sino que, al introyectar la opresión ${ }^{5}$, cada sujeta o sujeto la replicará en su praxis cotidiana, impactando a quienes le rodean. Como establece la filósofa Raquel Gutiérrez, "Quien domina necesariamente tiene que buscar que el dominado asuma sus puntos de vista y solo logre pensar con los esquemas y estereotipos del orden instituido que él se encarga de brindar" (211-212). Una vez que esto se logra, el camino para perpetuar el modelo está cimentado.

En un escenario como este, el saber y la teorización se vuelven dogmas y las subjetividades funcionales a esto, convirtiéndose en dóciles creyentes. Todo esto va a contribuir a que la realidad sea fetichizada. Esto quiere decir que, en la medida en que se posicione una sola manera de producir conocimiento sobre lo contingente, en la que la razón sea la jueza suprema y articuladora del mundo, y en la cual los saberes que de ahí se desprendan sean universales, necesarios y eternos, se refuerza la idea de que la realidad no puede ser cambiada. Si las maneras de interpretarla y de actuar en ella ya están dictadas de manera unívoca, lo que seamos capaces de leer y construir siempre va a ser reiteración de lo mismo, de lo ya existente, precisamente porque, al no permitir la ruptura, el desborde o lo imprevisto, el surgimiento de lo nuevo no tiene lugar. Así es como el pensamiento se vuelve conservador y servil a una forma opresora de entramarse con el mundo y actúa

5 La relación entre el ejercicio de prescripción y la introyección del opresor ha sido trabajada en profundidad por Paulo Freire. Al respecto es indispensable tener a la vista lo que desarrolla en Pedagogía del Oprimido. Allí señala "Su lucha [la de los oprimidos y oprimidas] se da entre ser ellos mismos o ser duales. Entre expulsar o no al opresor desde "dentro" de sí. Entre desalienarse o mantenerse alienados. Entre seguir prescripciones o tener opciones. Entre ser espectadores o actores. Entre actuar o tener la ilusión de que actúan en la acción de los opresores. Entre decir la palabra o no tener voz, castrados en su poder de crear y recrear, en su poder de transformar el mundo" (46). 
no solo sobre lo que sabemos, sino también sobre lo que somos capaces de soñar, lo que identificamos como viable. En directa relación con esto, Donna Haraway hace hincapié en cómo la emancipación precisa transgredir los mandatos reduccionistas de la subjetividad moderna. "La liberación - dice- se basa en la construcción de las conciencias, de la comprensión imaginativa de la opresión y, también, de lo posible" (14).

Si bien puede parecer "Perogrullo", es necesario hacer notar la falacia que fundamenta aquellas argumentaciones que pretenden justificar la validez del proyecto epistemológico imperante a partir de cómo él se encuentra globalizado, aludiendo a una especie de naturalización de la razón como jueza incuestionable de los vínculos que se establecen entres seres y el mundo, pasando convenientemente por alto que esta disposición epistémica fue instaurada tras un proceso de colonización. Tal como clarifica Alejandra Ciriza:

La universalización de este paradigma no es porque le sea inherente, sino porque hay razones materiales específicas que forjaron la mundialización de él. Razones que no responden a lógicas dialógicas de intercambio, sino a la expansión que a través de la conquista, con todo su repertorio de dominación, explotación, saqueo, aculturación y exterminio, impuso su cultura de la ilustración como "la cultura" (95).

Hacer esta precisión nos permite ir dilucidando la concepción de poder que se engendra a partir de este entramado epistemológico.

Teniendo en cuenta lo explicitado, no son las capacidades de las subjetividades en ejercicio y despliegue lo que va a configurar al poder. Es decir, no es el poder-hacer, el poder en tanto potencia lo que se fomenta. Lo que se instala y ejecuta es el poder que jerarquiza y subyuga, es decir el poder-sobre, el poder en tanto potestas. Por ello centraliza y acumula volviéndose una eterna repetición de lo mismo. La existencia de lo diverso o de lo caótico lo fragiliza, poniendo en riesgo su versión totalizante. De ahí que sea incapaz de soportar una crítica verdadera y proceda a aniquilar cualquier propuesta que lo desafíe o resquebraje su prevalencia. Dice la filósofa y matemática:

El poder, entonces, en tanto poder-imposición, se concibe de modo abstracto como posibilidad de normar, de instituir trayectorias 
obligadas para los individuos-átomos, como capacidad potencial de imponer destinos. Y los presentes impuestos o los destinos imaginados quedarán regidos, se encuadrarán, en un orden aceptado como natural, o al menos como necesario y, por supuesto, preexistente (Gutiérrez 224).

De ahí el urgente llamado ¡a desordenar! que promulga la teórica, como apertura prometedora que posibilitaría pensar más allá de los esquemas conceptuales hegemónicos, que solo obstaculizan las creatividades, respuestas y apuestas.

\section{A subvertir el orden impuesto: poner el cuerpo como consigna}

Teniendo en consideración lo ya explicitado, es indispensable poner atención a lo que sucede con aquel elemento cuya doblegación se encubre, a pesar de que paradójicamente sea lo que sostiene y posibilita la instalación de este modelo. Nos referimos al cuerpo y, con ello, a las afectividades que porta. Sin embargo, antes de continuar, es preciso introducir un elemento relacionado con el ejercicio del poder imposición que posibilitará una explicación más aguda.

Por más abrumadora que resulte la violencia con que se ejerce la praxis dominadora, es necesario recordar que tanto el poder imposición como la sumisión no son entidades abstractas que sobrevuelan el mundo. Por el contrario, ambas perspectivas y ejercicios configuran ante todo una relación doble. Es decir, por una parte está el opresor y por otra quién padece el abuso. Victimario y víctima. Tanto el uno como la otra son imprescindibles para que la dominación tenga lugar.

Lo que es necesario especificar es que, tal como reflexiona Raquel Gutiérrez durante su experiencia de cinco años de prisión política en Bolivia, este vínculo debe ser leído más allá de una escisión dicotómica en la que quién detenta el poder estaría en la condición de sujeto protagónico, aquel que lleva a cabo la acción; y su contraparte no sería más que un objeto que soporta en una inactividad total la acción de vulneración. Para Gutiérrez, las víctimas también son sujetos y sujetas que despliegan acciones, aunque éstas muchas veces no sean explícitas o impliquen una omisión. Tal como indica, "los oprimidos no son solamente objeto de opresión, sino también sujetos que de uno u otro modo eligen 
la pasividad, optan por delegar la gestión de su presente y su destino en manos ajenas. La sumisión no es solo el resultado de un acto de opresión: es, al mismo tiempo, una opción elegida frente a él" (125).

Es imperioso recalcar que con esto no se pretender responsabilizar de su opresión a quienes la padecen. Claro está que, en una situación de vulneración, las posibilidades de elegir no son en libertad, sino que están atravesadas por el miedo y una serie de consecuencias que se experimentarían si se osara desafiar el mandato de subyugación.

Lo que se busca poner en evidencia es que, para que la sumisión sea posible, se necesita quebrar, desarticular y formatear a la persona para que se doblegue. Esto requiere de acciones materiales y concretas (castigos, privaciones, violencia física), y al mismo tiempo de una institucionalidad que promueva una discursividad, un imaginario y una serie de relaciones de sentido que las respalden. Es decir, una epistemología que se edifique sobre el despojo epistémico y un amplio repertorio de violencia simbólica.

Si todos somos diversos en términos de identidades, temporalidad, cultura y territorialidad, las formas de acceso a la realidad no pueden ser únicas. El saber posicionado desde allí, vale decir, en una tribuna de lo absoluto, necesario y universal, se sostiene necesariamente en la marginación y exclusión, y éstas no se ejecutan solo en el mundo de las idealidades, sino que se inscriben directamente sobre lo material, sensible y corpóreo.

Afirmar el cuerpo, partir desde su situacionalidad, materialidad y especificidad, revela esto. Es decir, cuando deja de invisibilizarse quedan al descubierto los marcadores que definen el lugar de cada persona en el mundo. Se hace patente en qué medida las características e identidades que cada sujeta o sujeto porta son negadas, despreciadas y excluidas por el poder. La interseccionalidad ${ }^{6}$ de la opresión de hace presente.

6 La noción de "interseccionalidad" (o de imbricación de opresiones — como la han llamado las feministas decoloniales, tales como Ochy Curiel (2007) - , que hoy tiene una gran incidencia dentro de los feminismos, fue propuesta originariamente por las feministas negras estadounidenses, precisamente para explicar cómo género, raza y clase se entraman generando una matriz que profundiza los niveles de dominación a partir de las características y del lugar social que cada una ocupa. Vale decir, bajo la civilización patriarcal, la experiencia de opresión que vive una mujer blanca con sus necesidades bá- 
La episteme hegemónica nos instala el desprecio por el cuerpo. Al lado de la razón que se pretende ilimitada, totipotencial y que nos conecta con aquella cuota de divinidad que cada uno posee - el alma inmortal-, el cuerpo aparece como lo contingente, irrelevante. Aquello que envejece, se pudre, se cansa. El cuerpo es una masa que requiere ser acicalada y modificada para que no ofenda o asquee, pues nos conecta con la negación del mundo y del orden, con la in-mundicia.

Esa repugnancia que se decreta sobre el cuerpo, sus flujos y reflujos, no es ni ingenua ni casual. El desprecio que se instala como modo de vinculación con el propio cuerpo lo deja desprovisto, pues no se reconoce como valioso. No obstante, el desprecio no es suficiente. Las subjetividades son escurridizas y suelen encontrar modos de quebrantar lo instituido. Para que el cuerpo y la afectividad sean fácilmente maleables por el poder es necesario instalar un sistema de clausura que neutralice la potencia transformadora a través de la naturalización del statu quo (Mizrahi 37). Ahí la culpa despliega una labor indispensable. A través de ella se inhibe la potencia, se frustran aspiraciones y, así, paso a paso, va negando la capacidad de hacer (Mizrahi 89), inmovilizando y sentenciando, una y otra vez, a la repetición del fracaso.

La capacidad dominadora de la culpa es tal que, como indica Margarita Pisano, el ordenamiento ético y simbólico hegemónico se edifica en función de ella (133). La culpa prescribe la privación y ésta es introyectada generando una escisión total entre la potencia y el acto, entre el deseo y el poder. Por eso a partir del sentimiento de culpabilidad no se desprenden usos creativos (Lorde 146), lo que tiene lugar bajo su amparo es una praxis alienada. Frente a esto, la obediencia acontece sin mucha resistencia.

Sin embargo y por más que el modelo de dominación se reactualice permanentemente, diversificando las formas en que es capaz de apropiarse de nuestra capacidad creadora (Gutiérrez 195), el cuerpo persiste en inventar fugas o encontrar fisuras que le posibiliten rebelar-

sicas resueltas, no es igual que aquella que experimenta una mujer negra y empobrecida. Al respecto se podría profundizar extensamente, no obstante este no es el lugar para hacerlo. Para una primera aproximación es oportuno revisar lo que Kimberlé Crenshaw (1996) ha planteado al respecto. 
se. $Y$, a pesar de que no tengamos "un registro racional y consciente de la protesta que encarna nuestro cuerpo" (Mizrahi 49), una y otra vez, a lo largo de su existencia, el cuerpo desafía al dominio que lo coarta.

Aceptar el papel que el propio cuerpo tiene en el desarrollo de nuestra vida y en el devenir de nuestra subjetividad genera una apertura a una fuente de sabiduría exquisita. Pisano plantea que el cuerpo es el instrumento con el que tocamos la vida, es nuestra primera naturaleza lo que nos permite acceder al mundo identificando sensaciones, deseos. Es nuestro informante, y por eso hay que saber qué siente. A partir de ese vínculo se genera el saber (93).

\section{Saberes implicados: erotismo, ira y esperanza}

$\mathrm{Si}$, como nos mencionaba recientemente Gutiérrez, la sumisión es una actitud frente a la opresión, es posible vislumbrar una apertura. Hay ahí el anuncio de algo otro. En la medida en que no es una sentencia absolutizada e inamovible, es posible modificarla. Y para ello es fundamental ratificar lo negado. Vale decir, poner el cuerpo.

Afirmar las corporeidades rompe con el mandato de la Ilustración y la modernidad, pues la racionalidad se deja de utilizar como la excepcional regenta que se ejecuta en pos del anticipo y control de la realidad. Es abrirse al desorden, dándole lugar al riesgo, a la incertidumbre, a lo ambivalente. Es permitir que el azar se cuele. Es lanzarse a la posibilidad de poner todo en jaque. Es volver a poner en el centro el preguntar más que el responder. Es propiciar la posibilidad de reflexionarnos y narrarnos desde la intuición y el resonar, transgrediendo las reglas lógico-formales del saber occidental. Es apostar a hacer un proceso de desprendimiento para buscar otras maneras de ser libres y no funcionales a la dominación. En directa relación con esto, Liliana Mizrahi invita a:

Crear. Recrear. Inventar. Transformar. Probar. Ensayar. Multiplicar, imaginar, arriesgar nuevas respuestas, nuevos nombres, nuevos códigos, nuevos gestos. Corregir mentiras. Trascender el juego perverso de las apariencias. No complacer lo absurdo. Querer saber más allá de lo que nos conviene saber. Convertir la incertidumbre en el motivo de una creación constante. Imaginar mundos nuevos para poder descubrirlos (75). 
Esto no quiere decir que, entonces, haya que censurar y renunciar a cualquier manifestación de la razón. La apuesta radica en volver a construir desde la integralidad de las capacidades humanas, entre las cuales la racionalidad es solo una de ellas. También está el imaginar, el relacionarse, el sentir, el vibrar. Para actuar y conocer la realidad, "la curiosidad - dice Claudia Korol— es un motor tan importante como la necesidad y el deseo" (2007 20).

Reinvidicar la centralidad que tienen los cuerpos y afectividades en nuestro estar en el mundo no solo es una invocación al caos y la creatividad. El lugar que damos al cuerpo es fundamental, porque condiciona las formas de conciencia que podamos tener. Al respecto Lorena Cabnal es precisa:

Asumir la corporalidad individual como territorio propio e irrepetible, permite ir fortaleciendo el sentido de afirmación de su existencia de ser y estar en el mundo. Por lo tanto emerge la autoconciencia, que va dando cuenta de cómo ha vivido este cuerpo en su historia personal, particular y temporal, las diferentes manifestaciones y expresiones de los patriarcados y todas las opresiones derivadas de ellos (22).

Dicho de otro modo, la apertura que engendra la recuperación de lo sentipensante permite disputar el proyecto antropológico promovido por la matriz de sometimiento que impera.

Cabe mencionar que estos planteamientos no son algo nuevo. Las mujeres y feministas de nuestra América llevan años apostando a poner en el centro al cuerpo y los sentires. Sin ir más lejos, Berta Cáceres, como nos recuerda Francesca Gargallo, planteaba que conocer, tocar, mirar y hablar de nuestros cuerpos es una práctica que libera a las mujeres, es decir, es un ejercicio revolucionario (347). Y a partir de esto se permite internalizar ya no solo el deber sino también el placer. De este modo, se vuelve una praxis emancipadora en la medida en que posibilita la sanación de la violencia que se ha recibido e introyectado?

$7 \quad$ De ahí que no sea casual que luchadoras como Lorena Cabnal sean parte de La Red de Sanadoras Ancestrales de Iximulew, y que posicionen a la sanación como un camino cósmico político (2010). 
Esta defensa del placer, del deseo, de la vibración de los cuerpos, genera una reconexión con el erotismo. Lo erótico no se circunscribe a lo sexual, esa es una manera reduccionista y mercantilizada de verlo, servil a las lógicas opresoras que configuran subjetividades desconectadas de sus necesidades y emociones. "Lo erótico - dice Audre Lorde- no sólo atañe a lo que hacemos, sino también a la intensidad y a la plenitud que sentimos al actuar" (39).

La pulsión tiene un destino ético porque convoca al deseo a crear, a transformar, a desordenar y subvertir aquello que está amenazando la vida (Rolnik 2018). El erotismo alberga un espacio entre la autoconciencia y el desborde de las afectividades. Cabe recordar que "erótico" viene de eros, quien precisamente ha nacido de Caos (Lorde 40). De ahí que se conciba como aquella energía vital profundamente creadora, pensante y sintiente que portamos, y que potencia aquello que hacemos (Cabnal 24). El erotismo se vuelve una invitación a reconectarse con el vibrar propio. En esta línea, la recomendación de Gloria Andalzúa es categórica "No creas en el papel, sino en tus entrañas, en tus tripas" (44).

A partir de estas acciones y vínculos se transforman las subjetividades. Entonces, los saberes, conocimientos, las formas de nombrar la realidad que esas personas generen no pueden ser los mismos instalados bajo los designios de la epistemología hegemónica y su sujeto predilecto. Las reflexiones que surgen desde la vibración de las afectividades tienen necesariamente otras características e intensidades, porque emergen desde la modificación de la disposición epistémica, de ese colocarse frente a la realidad. Es decir, son saberes paridos desde el resquebrajamiento del orden. Cabe mencionar que esto no implica un juicio de valor, ni una nueva jerarquización. En ningún momento se ha explicitado que estos conocimientos sean mejores o peores que los otros, simplemente son diferentes.

De hecho, no son saberes centrados en lo puramente cognitivo, son saberes-del-cuerpo. Donde esté, el cuerpo entrega el ritmo, el pulso vibrátil (Rolnik 2018). En ese saber, su validación o eje no radica en la coherencia ni en las estructuras lógicas de los argumentos, sino en la implicancia que los engendra y que permite que nos sintamos y seamos sujetos históricos (Pisano 90) 
La implicancia promueve una praxis crítica que evita que la incomodidad sea eludida. Al contrario, le da un lugar y la profundiza, transformándola en un motor que posibilita tomar conciencia de las formas en que el poder dominación se hace presente en el funcionamiento de la realidad y en las subjetividades. La incomodidad permite desentrañar los mecanismos de encubrimiento que el poder instala, revela la intencionalidad perversa de su naturalización y nos muestra cómo cada persona se ha posicionado frente a él, ya sea padeciéndolo, desentendiéndose o, incluso, promoviéndolo. Así es como la incomodidad se vuelve ira y, desde allí, emanan saberes iracundos.

"La ira está cargada de información y de energía" (Lorde 142), surge frente a dolor que el dominio produce. Es la vibración frente a la injusticia, una energía que confronta al orden, y que, a pesar de lo caótica y dispersa que puede ser, remece. La ira no permite indiferencia, irrumpe y muchas veces contagia, sobre todo cuando su fuente es una violencia compartida, experimentada por muchas y muchos. Y urge socializarla.

Cuando se colectiviza ese vibrar, se comprende y reorganiza, la potencia de la ira se magnifica transformando lo que la rodea. Se vuelve fuente de saberes que transgreden con lo impuesto. Negar la ira es resignarse, es perseverar en la sumisión, es cerrarse al conocimiento que emerge desde la incomodidad. Dice Audre Lorde, "la ira compartida entre iguales engendra cambios, no destrucción, y la incomodidad y el daño que a menudo causa no son señales mortíferas sino de crecimiento" (147).

Sin embargo, la agitación e irritabilidad que genera la incomodidad no solo conecta con aquellas instancias dolorosas que la dominación ocasiona. Es decir, no solo se queda en el ámbito de la denuncia, sino que también propicia el anuncio. El malestar propio del incomodarse pone en movimiento y gesta desacatos que, aunque a veces son imperceptibles, en la medida que se van haciendo conscientes y se organizan entretejen resistencias y alimentan rebeldías. Así, comienzan a ser las propias esperanzas las que nos condicionan (Andalzúa 36)

A partir de esta disposición afectiva se gestan saberes utópicos que anuncian mundos otros. Plenos de deseos, rebosantes de anhelos, los saberes esperanzados transforman las subjetividades en la medida en 
que permiten imaginar y ensayar modos de ser y habitar el mundo, en los que los vínculos que se forjen no apuesten a la sumisión sino a formas de crear y recrear emancipaciones. Pero no por esto son ingenuos. Los saberes esperanzados saben que no son suficientes para derrotar a la macro cultura del dominio. No obstante, en estos tiempos de desencanto y aislamiento, la necesidad de nombrarlos y constatar su existencia es indispensable, porque evidencian que no solo la subjetividad del poder imposición es posible. Desde las fisuras y los intersticios del poder surgen otras formas de parirse al mundo que, desde un multiforme y afectado desorden, apuestan a construir capacidad de hacer, autodeterminación y libertad (Gutiérrez 156).

\section{A modo de cierre}

Más que entregar conclusiones o certezas absolutas que se desprendan de lo explicitado, es pertinente, a modo de cierre, realizar una síntesis de los ejes prioritarios, indicando un par de desafíos que se levantan a partir de esto.

Para comenzar y a pesar de que pueda resultar reiterativo, es indispensable insistir en la intencionalidad política que posee toda matriz epistémica, que se expresa en la instalación de un proyecto antropológico específico y que promueve modos de vinculación afines. En la medida en que la epistemología condiciona cómo nos entramamos con la realidad, su funcionamiento y despliegue permite la naturalización del modelo imperante. Para ello promueve la adaptación a él y ejecuta una serie de estrategias que tienen como objetivo su introyección.

En el caso del modelo civilizatorio de dominación que habitamos, su ordenamiento, en tanto mundo, está basado en una preponderancia totalizante del análisis. A través de esto se esencializa una manera dicotómica de leer - y actuar en- el mundo, que jerarquiza las diferencias absolutizando estereotipos, imaginarios y sentidos. De ahí que los vínculos fomentados sean funcionales a la subordinación, a la fetichización de la realidad y a la reiteración de las lógicas de sumisión.

El espectro de prácticas que se desprenden de un patrón como este instala un ejercicio del poder como dominación, el cual se centraliza y despliega desde una tribuna autoritaria: la del orden. De este modo, 
se inhibe la posibilidad de conectar con un poder creador, disperso y multicéntrico.

La instalación del poder dominación recurre a una utilización ambivalente del cuerpo. Ya que, por una parte, discursivamente lo corpóreo se niega y desprecia. No obstante, por otra, el ejercicio de la opresión y explotación solo logra imprimirse en nuestras subjetividades mediante el control y moldeamiento de los cuerpos y afectividades.

Sin embargo y a pesar de todos los dispositivos de domesticación que nos circundan, la rebeldía y el caos siguen colándose por nuestros poros. Emergen una y otra vez nuevas formas de desobedecer y reconectar con una energía vibrátil, creadora, implicada. En el encuentro de ese pulsar se gestan nuevos saberes, conocimientos, sentidos e imaginarios que exceden lo establecido y posibilitan la irrupción de lo nuevo.

Teniendo en cuenta esto, hay dos desafíos que se abren. El primero se vincula con la urgencia por generar una apertura a nuevos formatos para compartir y visibilizar saberes. Si el interés está puesto en permitir que "hable" el potencial expresivo de los cuerpos y sentires, es indispensable recuperar aquellos modos de comunicación que han sido despreciados por los centros predilectos del saber. Volver a dar un lugar a la oralidad, los tejidos, la danza, las performances, los trenzados y tantos otros modos de expresión que emanan como saberes del cuerpo vibrante. La escritura es exquisita, eso no está en cuestión, pero es solo una más de las tantas formas de volcarnos al mundo que existen.

Finalmente, como segundo desafío y (auto)recomendación, es oportuno recordar la importancia de cultivar con terquedad una sospecha epistémica sistemática y radical que sepa posicionarse frente a los absolutos o las certezas incuestionables. Poner atención a dónde se dirige la mirada, el sentir. Qué cuerpo y subjetividad se está promoviendo, cuáles quedan en desmedro. La apuesta por abandonar la ansiedad, la sensación de control y la rigidez de los dogmas, para arrojarse al riesgo del desborde.

\section{Bibliografía}

Andalzúa, Gloria. Hablando lenguas: una carta a escritoras tercermundistas. Oaxaca: Fusilemos la Noche, 2017. 
Cabnal, Lorena. "Acercamiento a la construcción del pensamiento de las mujeres indígenas feministas comunitarias de Abya Yala". Feministas siempre. España: Acsur, 2010.

Ciriza, Alejandra. "Construir genealogías feministas desde el sur: encrucijadas y tensiones". MILLCAYAC - Revista Digital de Ciencias Sociales II/3 (2015): 83-104.

Crenshaw, Kimberlé. Mapping the Margins: Intersectionality, Identity Politics, and Violence Against Women of Color. Critical Race Theory. The key writings that formed the movement. Kimberlé Crenshaw, Meil Gotanda y otras, editoras. Nueva York: The New Press, 1996.

Curiel, Ochy. "Crítica poscolonial desde las prácticas políticas del feminismo antirracista". Nómadas 26 (2007): 97-101.

Duarte, Claudio. "Sociedades adultocéntricas: sobre sus orígenes y reproducción”. Última década 36 (2012): 99-125.

Fanon, Frantz. Los condenados de la tierra. México: Fondo de Cultura Económica, 1983.

Federici, Silvia. El calibán y la bruja. Mujeres, cuerpo y acumulación originaria. Buenos Aires: Tinta Limón, 2010.

Freire, Paulo. Pedagogía del Oprimido. Buenos Aires: Siglo XXI, 2006.

Gargallo, Francesca. Feminismos desde Abya Yala. Ideas y proposiciones de las mujeres de 607 pueblos en Nuestra América. Santiago: Editorial Quimantú, 2013.

González, Lorena. Configuración de una Epistemología Situada de la Resistencia: prácticas intelectuales y producción de saberes para la transformación social de Nuestra América. (Tesis doctoral). Universidad de Santiago de Chile, 2017.

González, Lorena. "De afectividades, desobediencias, rebeldías y emergencias". Revista de Estudios Avanzados 30 (2018): 11-22.

Gutiérrez, Raquel. ¡A desordenar! Por una historia abierta de la lucha social. Argentina: Tinta Limón, 2016.

Haraway, Donna. Manifiesto ciborg. El sueño irónico de un lenguaje común para las mujeres en el circuito integrado. España: Kaótica Libros, 2020.

Korol, Claudia. 'La educación como práctica de la libertad' Nuevas lecturas posibles". Hacia una pedagogía feminista. Géneros y educación popular. Pañuelos en Rebeldía, editores. Buenos Aires: Editorial el Colectivo y América Libre, 2007. 
Korol, Claudia. "Una perspectiva feminista en la formación de los movimientos populares: la batalla simultánea contra todas las opresiones". Revista Venezolana de estudios de la mujer 13/31 (2008): 27-39.

Lorde, Audre. La hermana, la extranjera. Artículos y conferencias. Traducción de María Corniero. Madrid: Horas y Horas Editorial, 2003.

Mizrahi, Liliana. Las mujeres y la culpa. Herederas de una moral inquisidora. Buenos Aires: Nuevohacer, 2003.

Pisano, Margarita. Fantasear un futuro: Introducción a un cambio civilizatorio. Chile: Editorial Revolucionarias, 2015.

Rolnik, Suely. “¿Cómo hacernos un cuerpo?” (Entevista realizada por Marie Bardet). Lobo suelto. 8 de mayo del 2018. Disponible en http://lobosuelto.com/como-hacernos-un-cuerpo-entrevista-con-suely-rolnik-marie-bardet/

Rolnik, Suely. Esferas de la insurrección. Apuntes para descolonizar el inconsciente. Buenos Aires: Tinta Limón, 2019.

Wallerstein, Immanuel. Conocer el mundo, saber el mundo. El fin de lo aprendido. Una ciencia social para el siglo XXI. Ciudad de México: Editorial Siglo XXI, 2001.

Zemelman, Hugo. "Pensar teórico y pensar epistémico: los retos de las ciencias sociales latinoamericanas". Conferencia Magistral, Universidad de la Ciudad de México, Volumen 10. Ciudad de México: IPECAL, 2001

Zemelman, Hugo. "Sujeto y subjetividad: la problemática de la construcción de alternativas como construcción posible". Polis, Revista de la Universidad Bolivariana 9/27 (2010): 355-366. 